\title{
Abortions in Urban and Rural Aereas Due to Gender
}

\section{Brikena (Buda) Dhuli}

\author{
University of "Aleksandër Moisiu" Durres; kenadhuli@yahoo.com
}

\section{Doi:10.5901/ajis.2016.v5n1p47}

\begin{abstract}
A phenomenon which recently has become almost usual is termination of pregnancy. About $15 \%$ of pregnancies end in miscarriage. Some of them occur so early that some women do not realize that are having a miscarriage. Part of them occurs before the 12th week. The main cause of abortion is normal fetal underdevelopment and damage of the genetic structure. But the data show that half of abortions are performed after the 12th week of pregnancy, due to unwanted sex of the child. Interruptions made beyond this period, because sex is determined after the 12th week, would be called criminal interference. Terminations of pregnancy figures made on this purpose are high. This has made Albania to be part of the problem reported to the Council of Europe. Prohibition of ultrasounds that indicate the sex of the baby in the womb is supported by the majority of gynecologists in the country, who say that Albania should adopt a law stoping mothers to see sex of the child, to prevent abortion if the child is female. The performance of abortion in our country is allowed until the 12th week. Nothwithstanding this, it has been proved that abortion is associated with psychological consequences, social and health.
\end{abstract}

Keywords: abortion, psychological consequences, social, genetic structure

\section{Psychological Reactions to Abortion}

From observations of some women who have had an abortion it is noticed that a part of them feel relief and seem to have escaped from a burden that could have repercussions on family and social life. Another considerable group of women present guilt, sadness and loss. This fact makes it an imperative need for them to consult with social worker $I$ psychologist, both before and after the abortion.

From observations of controversial cases remains problematic the reaction of the male partner to abortion. Men initially can address the problem calmly leaving the choice up to the wife / partner. There are others who earnestly seek termination of pregnancy. But over time feelings appear to change showing the true feelings. Males begin to experience feelings similar to those of women; guilt, anger and sadness to anger ${ }^{1}$

Due to selective abortion in Albania more men than women are born. In our country, for the period 2008-2010, the ratio of male birth marks an average of 111.7 per 100 female births. Meanwhile, the global rate is 105 male births per 100 female births and the study confirms that this balance is broken in Albania precisely because of the increasing cases of selective abortion. The desire to have at least one male successor in the family is the leading cause of infant deliberate abortions of girls. Albania takes first place for this indicator in the Balkan area, followed by Northwestern Macedonia. This is the situation validated by the results of the report, confirming an unbalanced situation in the birth rates between the sexes.

According to this report it seems that parents from urban areas have more often selected the sex of the child than parents in rural areas, who simply prefer to give birth to more children. The findings show how boys as well as girls are perceived as valuable in the family. Here we come to the conclusion that cultural factors that affect the need to have boys is connected to the legacy and and protection of the family. On the other side, boys have more economic advantages than girls, because they can emigrate and support the family.

Albanian society accepts more the lack of a woman, rather than the lack of a boy. Representatives from the Ministry of Health were present during the presentation of this report, which is the first in Albania. The ministry considered sex selection as a deed condemned by the law. These are some of the conclusions of the study "unbalanced ratio between the sexes at birth in Albania", presented by the Ministry of Health, with the support of organizations "UNFPA" and "World Vision".

${ }_{1}^{1}$ Raport i paekuilibruar në lindje midis dy sekseve në Shqipëri”, përgatitur nga Ëorld Vision dhe UNFPA, Tiranë 2012, fq.5-6) 


\section{Points of View Against Abortion}

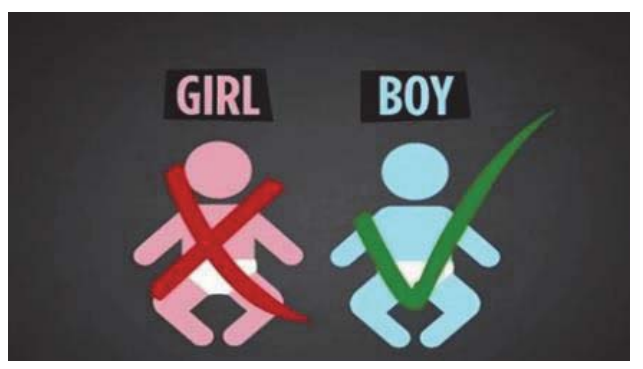

In the above survey in order to measure if Albanians consider abortion as an option to limit fertility, respondents were asked if they thought that a woman has in any case the right to decide about her pregnancy, including here the right to abortion or not. The study revealed that around three quarters of women (72\%) think that a woman has the right to take a decision on her pregnancy, including abortion. Almost all the other women believe that abortion is acceptable in some circumstances (26\%).

The opinion that abortion is a decision of a woman not highly influenced by demographic characteristics, but nevertheless was more prevalent among women who had completed a bachelor degree than high school (78\%) and less prevalent among women with a lower socio-economic status (69\%). Fewer men interviewed said that abortion is always a personal choice for women (53\%), but as many others believe that it is acceptable in certain situations, then the percentage of those who believe that it is never acceptable is almost equal to that of women surveyed (1\%).

Acceptability of abortion from Albanian men ranges as per the social status, residence and age. It was high in urban areas, except Tirana (61\%) and lowest in men aged about $45-49$ years (44\%). Respondents who did not think that a woman is always right to decide about abortion were asked about the admissibility of abortion under such conditions as specific as risk to the woman's life, risk to women's health, deformation of the fetus, pregnancy due to rape, pregnancy outside of marriage and the inability to keep the first baby and / or another child. Selected circumstances can be grouped into three levels of admissibility in both men and women.

Women identified as less acceptable the reason for an abortion being unmarried or inability to keep a child (respectively $38 \%$ and $22 \%$ ). Lack of money to raise a child was a reason against abortion, the highest compared to the response in "depends" or "do not know" (59\%). The second level of acceptability of the women interviewed had to do with the situation in which the pregnancy resulted from rape or because of health problems (respectively $53 \%$ and $59 \%$ ). About one in five women surveyed who answered these questions, thought that abortion was not justified in these circumstances. The highest level of acceptability of abortion women interviewed was for pregnancies in which the fetus had any kind of deformation (70\%), or for those pregnancies that threaten the lives of women (80\%). One in ten women felt that a woman should keep her pregnancy to the end even though it is at risk of life and $19 \%$ felt that a woman should also continue her pregnancy if the fetus was physically deformed. Men asked on the same issue for the admissibility of abortion were more or less of the same opinion with women.

However, compared with the women interviewed men disagreed less to an abortion when there is no financial support to raise the kid and more when a woman is not married. Men acceptability was also lower when the fetus is deformed.

Men praised most the life and health of women receiving abortion in cases where the health (74\%) or lives (87\%) of women were at risk. While many think that abortion is a personal decision of the woman, in the case of an unwanted pregnancy most Albanian women tend to say that a woman should keep the child and raise herself (71\%) and only a minority think she should have an abortion (21\%). Only 2\% thought that a wife can give her baby up for adoption. Women who think that a woman should give birth and keep her child are mainly those living in rural areas. The percentage decreases with increasing education and socio-economic status of women. Men are less likely to say that a woman should give birth and keep an unwanted child (40\%). Adoption as a way to act is more supported by men than by women (10\% versus $2 \%)$. Men who live in Tirana and other urban areas, as well as those better educated and with a certain 
socio-economic status are more likely to say that a woman should have an abortion².

In Kosovo, there have been several studies on the overall health and reproductive health, including the health issues of women and men as well as abortion. UNFPA estimates (2000) show that for every 100 live births 4.8 abortions are carried. In 2002, UNFPA reported 5 abortions for every 100 live births. Both estimates are data collected from general hospitals, but not private clinics. Considering that a large number of abortions are performed in private clinics, the statistics are not complete. None of these studies did cover the issue of abortion deeply. The general social attitudes to abortion, the reasons and consequences have not been documented ${ }^{3}$.

Termination of pregnancy for medical reasons, abnormal fetal development and in some cases even rape, are generally accepted by the participants. However, some participants considered abortion and reasons why you come to abortion as 'nonsense'. When comparing the results of the survey on opinions on abortion, women from Prishtina are different from women of all other countries in the Albanian speaking communities. Women living in Prishtina believe that abortion should exist as an option, especially when considering the difficult financial situation. According to some of them, if abortion would not exist as an option, increasing poverty will suffer tremendous change. When imagining themselves in different situations, most of them agreed that abortion should exist as an option. Women living in urban areas in general consider abortion normal when the reason for abortion is valid. Although they would not like to have an abortion, they accept abortion as something that should be done. Women living in urban areas do not hesitate to talk about their experience with abortion while women in rural areas were more conservative. ${ }^{4}$

Most women and men agree that if a man refuses to raise his child, abortion should be acceptable. This was the most common reason why unmarried women decided to have an abortion. The local mentality is that children raised by only one parent, even in good living conditions, are always excluded and discriminated by elders and peers. Women claim that one of the reasons why married women have an abortion is this discrimination. According to them, people tend to label and call these children with different names, such as 'bastard'. According to actual Law on Interruption of Pregnancy, "abortion should be performed at the request of the woman within 10 weeks of pregnancy. No written consent or waiting; parental consent is required for minors under 16 years of age. "However, some anecdotal evidence indicates that some private clinics in urban areas, do abortions later in pregnancy. Women who participated in focus groups tell about cases where their acquaintances or relatives had abortions after the third month of pregnancy. It is said that private clinics do abortions in the fifth or later in pregnancy, especially if the doctor is close to the patient or if you pay a high fee for the abortion.

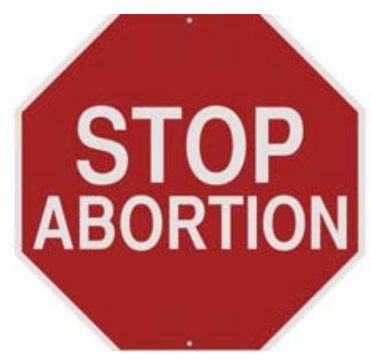

\section{References}

Unbalanced birth ratio between both sexes in Albania ", prepared by World Vision and UNFPA, Tirana 2012 fq.5-6)

Pregnancy and Family Planning in Kosovo

http://www.shendetesia.gov.al/files/userfiles/Baza_Ligjore/Dokumenta_strategjike/ANALIZA_SITUATES_E_RIPUNUAR_mars_09.pdf http://www.unfpakos.org/wp-content/uploads/2012/05/PregnancyandFPיPinKosovo-Alb.pdf)

${ }^{4}$ (Shtatzënia dhe Planifikimi Familjar në Kosovë) 
